\title{
Lactate preserves neuronal metabolism and function following antecedent recurrent hypoglycemia
}

\author{
Raimund I. Herzog, ${ }^{1}$ Lihong Jiang, ${ }^{2}$ Peter Herman, ${ }^{2}$ Chen Zhao, ${ }^{1}$ Basavaraju G. Sanganahalli, ${ }^{2}$
} Graeme F. Mason, 2,3 Fahmeed Hyder, ${ }^{2}$ Douglas L. Rothman, ${ }^{2}$

Robert S. Sherwin, ${ }^{1}$ and Kevin L. Behar ${ }^{2,3}$

\begin{abstract}
'Department of Internal Medicine, Section of Endocrinology, ${ }^{2}$ Department of Diagnostic Radiology, Magnetic Resonance Research Center, and ${ }^{3}$ Department of Psychiatry, Yale School of Medicine, New Haven, Connecticut, USA.
\end{abstract}

\begin{abstract}
Hypoglycemia occurs frequently during intensive insulin therapy in patients with both type 1 and type 2 diabetes and remains the single most important obstacle in achieving tight glycemic control. Using a rodent model of hypoglycemia, we demonstrated that exposure to antecedent recurrent hypoglycemia leads to adaptations of brain metabolism so that modest increments in circulating lactate allow the brain to function normally under acute hypoglycemic conditions. We characterized 3 major factors underlying this effect. First, we measured enhanced transport of lactate both into as well as out of the brain that resulted in only a small increase of its contribution to total brain oxidative capacity, suggesting that it was not the major fuel. Second, we observed a doubling of the glucose contribution to brain metabolism under hypoglycemic conditions that restored metabolic activity to levels otherwise only observed at euglycemia. Third, we determined that elevated lactate is critical for maintaining glucose metabolism under hypoglycemia, which preserves neuronal function. These unexpected findings suggest that while lactate uptake was enhanced, it is insufficient to support metabolism as an alternate substrate to replace glucose. Lactate is, however, able to modulate metabolic and neuronal activity, serving as a "metabolic regulator" instead.
\end{abstract}

\section{Introduction}

Diabetic complications can be reduced by intensive insulin therapy that achieves near normalization of blood glucose levels. However, the benefits of such treatment regimens are limited by more frequent and severe bouts of hypoglycemia (1), which in turn diminish the capacity of the brain to detect hypoglycemia and activate counterregulatory defenses and neuroglycopenic symptoms, further increasing hypoglycemic risk (2). As a result, hypoglycemia often occurs without warning symptoms or during sleep, underscoring the importance of developing preventive strategies and of minimizing its potential acute adverse consequences. This is of particular concern in young children with diabetes, since hypoglycemia early in life can cause persistent brain damage, delay normal development, and result in cognitive impairment (3).

While the brain usually depends predominantly on glucose as an energy substrate, the brain can also use alternative fuels, such as the monocarboxylic acids lactate and $\beta$-hydroxybutyrate, to maintain its energy requirements. In keeping with this, humans can tolerate severe hypoglycemia during prolonged fasting without impairment in cognitive function due to the production of ketones (4). Provision of alternate fuels has been reported to improve cognitive dysfunction during acute hypoglycemia in both nondiabetic and diabetic humans (4-6). Thus, monocarboxylic acids might be protective against hypoglycemic injury in diabetic patients, particularly in those exposed to repetitive episodes of hypoglycemia, who are unable to experience warning symptoms that signal the need to eat. It has been previously reported that brain uptake and utiliza-

Authorship note: Raimund I. Herzog and Lihong Jiang are co-first authors. Conflict of interest: The authors have declared that no conflict of interest exists. Citation for this article: J Clin Invest. 2013;123(5):1988-1998. doi:10.1172/JCI65105 tion of the short chain monocarboxylic acid $\left[2-{ }^{13} \mathrm{C}\right]$-acetate, a predominantly astrocytic substrate, is increased in patients with type 1 diabetes during acute hypoglycemia (7). In a follow-up study, we characterized brain acetate metabolism in a rodent model of $\underline{3}$ consecutive days of recurrent antecedent hypoglycemia ( $3 \mathrm{dRH})$ that recapitulates the adaptations of brain metabolism associated with intensive insulin therapy in humans. In that study, we found that, when acetate metabolism in astroglia was saturated $(8,9)$, a neuron-specific TCA cycle flux reduction existed, suggesting that a substrate supporting neuronal metabolism, such as lactate, may be of particular benefit under hypoglycemic conditions (10).

Lactate has traditionally been considered a brain metabolic by-product when there is an excess of glycolysis in relation to mitochondrial oxidation, resulting in net lactate export from brain to plasma. However, recent studies by Tyson et al. (11) in rats and Boumezbeur et al. (12) in humans have shown label incorporation into glutamate and glutamine following infusion of $\left[3-{ }^{13} \mathrm{C}\right]$ lactate, suggesting that lactate itself can serve as a metabolic substrate. This view is further supported by data indicating that neurons may actually preferentially use lactate generated by astrocytes through local glycolytic activity (13) and that brain oxidative metabolism can be supported by the infusion of lactate into diabetic dogs during acute hypoglycemia (14).

The objective of this study was to define the adaptations of neuronal lactate metabolism to antecedent recurrent hypoglycemia in our $3 \mathrm{dRH}$ rodent model, which has been well characterized by our group to reproduce the central neurotransmitter and hormonal adaptations and characteristic loss of counterregulation to acute hypoglycemia (15-17). For this purpose, we used nuclear magnetic resonance spectroscopy to measure the concentrations and enrichment of energy substrates and their metabolites with 
A

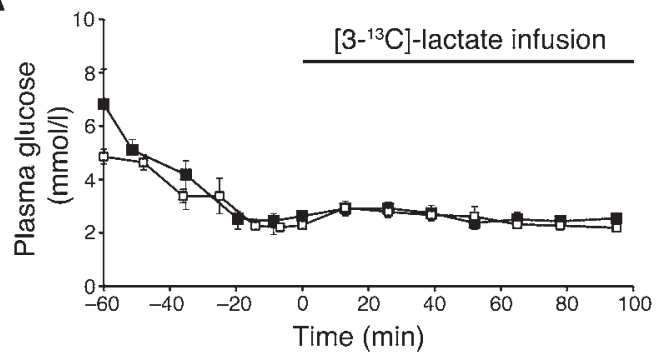

C

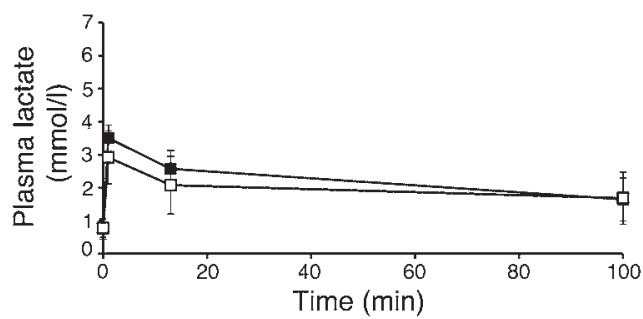

E

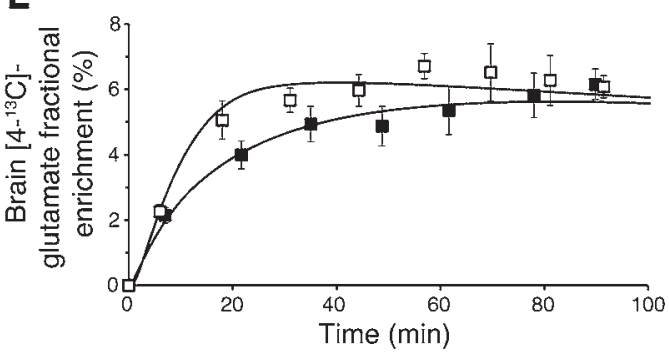

B

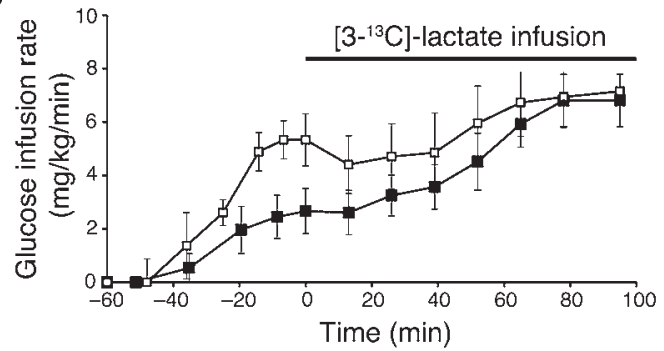

D

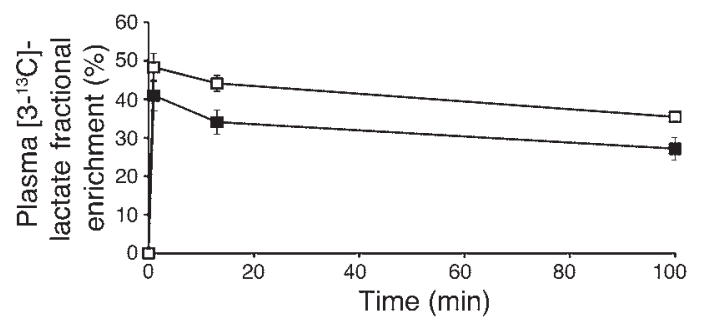

F

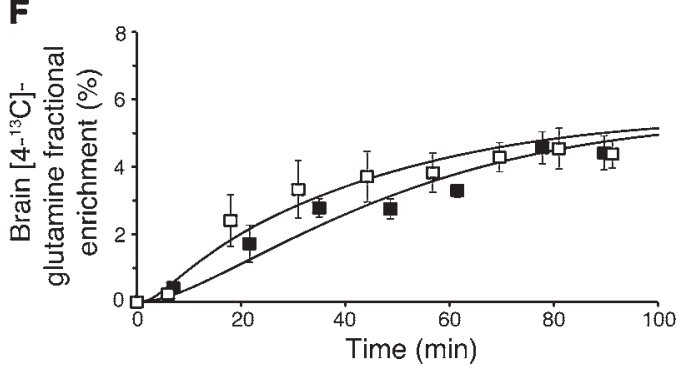

Figure 1

Under hyperinsulinemic-hypoglycemic clamp conditions and $\left[3-{ }^{13} \mathrm{C}\right]$-lactate infusion, animals preexposed to recurrent hypoglycemia show a markedly faster metabolite enrichment time course than controls. Shown here are group averages for (A) plasma glucose levels, (B) glucose infusion rates, (C) plasma lactate concentrations during tracer infusion, (D) plasma [3-13 C]-lactate enrichment, (E) brain $\left[4-{ }^{13} \mathrm{C}\right.$-]-glutamate enrichment time courses, and $(\mathbf{F})$ brain $\left[4-{ }^{13} \mathrm{C}\right]$-glutamine enrichment during tracer infusion (black squares represent control, white squares represent $3 \mathrm{dRH}$; $\left[3-{ }^{13} \mathrm{C}\right]$-lactate infusion begins at time $t=0$ minutes; data reflect mean $\pm \mathrm{SEM}$ of 6 animals per group).

the nonradioactive stable isotope carbon-13 over time. Specifically, we infused $\left[3-{ }^{13} \mathrm{C}\right]$-lactate to measure the appearance rate of ${ }^{13} \mathrm{C}$ label in the cerebral pools of glutamate and glutamine in our animal model of recurrent hypoglycemia and nontreated controls under different glycemic conditions. These time courses were then applied to a mathematical model of compartmentalized brain metabolism that uses numerical fitting to calculate the rates of mitochondrial substrate oxidation in astrocytes and neurons as well as glutamate neurotransmitter cycling $(18,19)$. A reversible MichaelisMenten model was used to describe lactate transport across the blood-brain barrier. Finally, we used an electrophysiological stimulus-response paradigm to correlate the metabolic findings with brain activity. Our results show that antecedent recurrent hypoglycemia facilitates neuronal uptake of $\left[3-{ }^{13} \mathrm{C}\right]$-lactate under hypoglycemia. This is accompanied by the ability of the recurrent antecedent hypoglycemia animals (referred to throughout as $\mathrm{RH}$ animals) to maintain euglycemic levels of glucose oxidation during hypoglycemia when lactate is elevated. The combination of both of these effects reverses the hypoglycemia-associated reduc-
Table 1

Ethanol-extracted brain metabolite concentrations at the end of the lactate infusion experiment measured by high-resolution NMR spectroscopy

\begin{tabular}{lcccc} 
Metabolite & $\begin{array}{c}\text { Control } \\
\text { euglycemic clamp }\end{array}$ & $\begin{array}{c}\text { Control } \\
\text { hypoglycemic clamp }\end{array}$ & $\begin{array}{c}\text { RH euglycemic } \\
\text { clamp }\end{array}$ & $\begin{array}{c}\text { RH hypoglycemic } \\
\text { clamp }\end{array}$ \\
Asp $(\mu \mathrm{mol} / \mathrm{g})$ & $2.9 \pm 0.3$ & $3.1 \pm 0.2$ & $1.4 \pm 0.3$ & $4.2 \pm 0.3$ \\
Glu $(\mu \mathrm{mol} / \mathrm{g})$ & $10.8 \pm 0.2$ & $9.7 \pm 0.6$ & $8.9 \pm 0.2$ & $12.1 \pm 0.3$ \\
Gln $(\mu \mathrm{mol} / \mathrm{g})$ & $6.6 \pm 0.1$ & $7.3 \pm 0.3$ & $5.4 \pm 0.2$ & $7.2 \pm 0.3$ \\
Lactate $(\mu \mathrm{mol} / \mathrm{g})$ & $1.42 \pm 0.26$ & $1.17 \pm 0.15$ & $1.12 \pm 0.18$ & $1.03 \pm 0.16$ \\
Glucose $(\mu \mathrm{mol} / \mathrm{g})$ & $1.35 \pm 0.11$ & $0.05 \pm 0.01$ & $1.77 \pm 0.05$ & $0.25 \pm 0.07$ \\
\hline
\end{tabular}

$\mathrm{RH}$, recurrent hypoglycemia. 
A

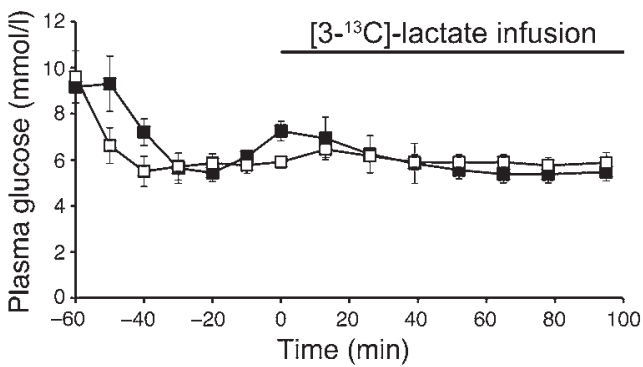

C

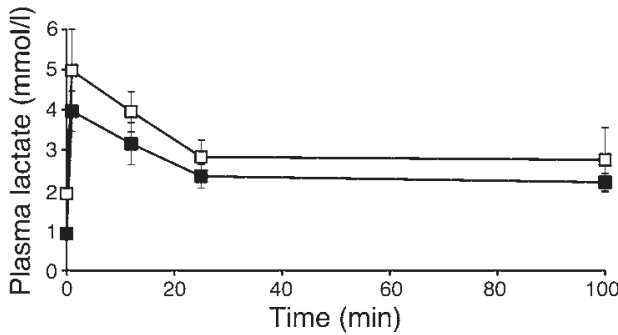

E

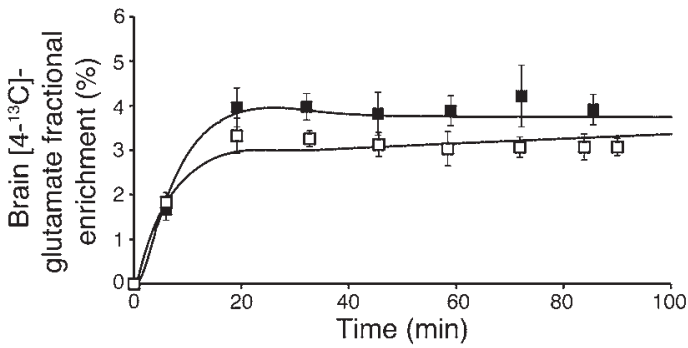

B

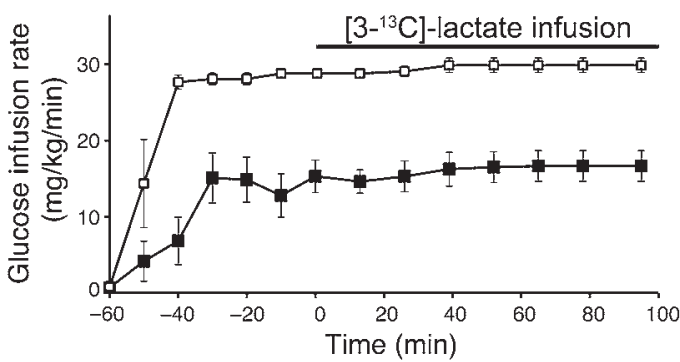

D

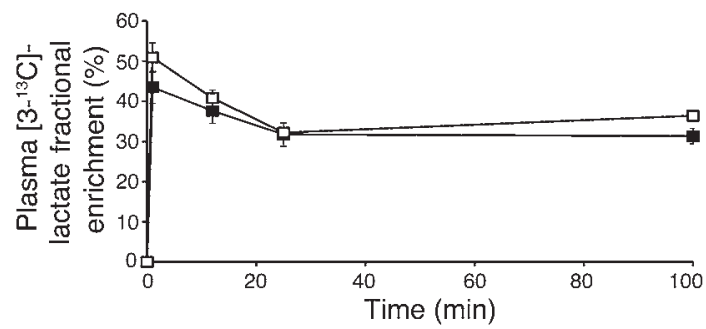

F

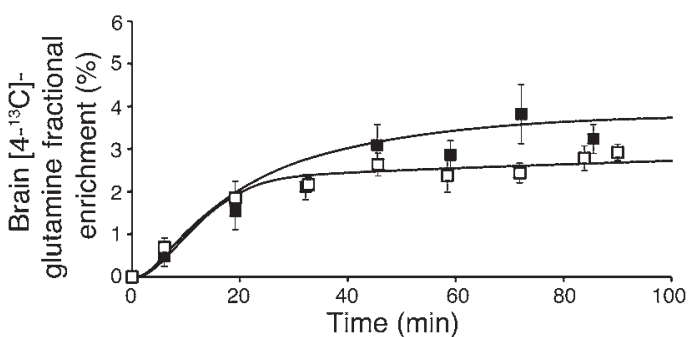

Figure 2

Under hyperinsulinemic-euglycemic clamp conditions and $\left[3-{ }^{13} \mathrm{C}\right]$-lactate infusion, control and $3 \mathrm{dRH}$ animals show similar metabolite enrichment time courses. Shown here are group averages for $(\mathbf{A})$ plasma glucose levels, (B) glucose infusion rates, (C) plasma lactate concentrations during $\left[3^{-13} \mathrm{C}\right]$-lactate infusion, (D) plasma ${ }^{13} \mathrm{C}$-lacate enrichment, $(\mathbf{E})$ brain $\left[4-{ }^{13} \mathrm{C}\right]$-glutamate enrichment time courses during $\left[3-{ }^{13} \mathrm{C}\right]$-lactate infusion, and $(\mathbf{F})$ brain $\left[4-{ }^{13} \mathrm{C}\right]$-glutamine enrichment during $\left[3-{ }^{13} \mathrm{C}\right]$-lactate infusion (black squares represent control, white squares represent $3 \mathrm{dRH}$; $\left[3^{-13} \mathrm{C}\right]$-lactate infusion begins at time $t=0$ minutes; data reflect mean \pm SEM of 6 animals per group).

tion in neuronal mitochondrial oxidation observed in acutely hypoglycemic control and $3 \mathrm{dRH}$ animals and further allowed the $3 \mathrm{dRH}$ animals to maintain a normal neural activity response to sensory stimulation during hypoglycemia. Based on these observations, we propose that measures that result in a mild rise in lactate levels may be beneficial in the context of recurrent hypoglycemia because they stimulate the utilization of glucose by the brain under hypoglycemia and provide an additional energy source to sustain brain activation.

\section{Results}

To investigate the impact of antecedent exposure to hypoglycemia on brain lactate metabolism, sodium $\left[3-{ }^{13} \mathrm{C}\right]$-lactate was infused into control (Ctrl) rats and rats exposed to insulin-induced $3 \mathrm{dRH}$ under hyperinsulinemic-hypoglycemic (HYPO clamp) as well as hyperinsulinemic-euglycemic (EU clamp) conditions. The latter was required, since under fasting euglycemic conditions, a substantial proportion of infused $\left[3-{ }^{13} \mathrm{C}\right]$-lactate was converted to $\left[1,6-{ }^{13} \mathrm{C}\right]$-glucose via peripheral gluconeogenesis, thereby making it impossible to distinguish the contribution of glucose from that of lactate to brain metabolite labeling (Supplemental Figure 1; supplemental material available online with this article;
doi:10.1172/JCI65105DS1). This confounding effect was eliminated during a hyperinsulinemic-euglycemic clamp, which suppressed gluconeogenesis, allowing us to study the contribution of labeled lactate alone.

Clamped hypoglycemia. A constant $50 \mathrm{mU} / \mathrm{min} / \mathrm{kg}$ insulin infusion and a variable $20 \%$ dextrose infusion were used to lower plasma glucose to a stable hypoglycemic level of $2.5 \mathrm{mM}$ (Figure 1A). Prior to the $\left[3-{ }^{13} \mathrm{C}\right]$-lactate infusion, $3 \mathrm{dRH}$ animals required a higher glucose infusion rate than control animals (Figure 1B), consistent with their failure to mount a counterregulatory response.

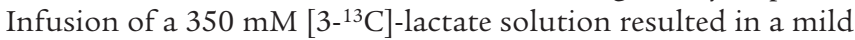
increase in baseline plasma lactate concentration to approximately $3 \mathrm{mM}$ for both control and $3 \mathrm{dRH}$ animals (Figure 1C). Fractional ${ }^{13} \mathrm{C}$ enrichment of plasma lactate reached $35 \%-40 \%$ in both groups (Figure 1D). The delivery of $\left[3-{ }^{13} \mathrm{C}\right]$-lactate resulted in a transient decrease of the glucose infusion requirement, particularly in $3 \mathrm{dRH}$ animals, suggesting a glucose-sparing metabolic effect (Figure 1B). There was no difference in the proportion of dilutional inflows into the TCA cycle between groups, as evident from the comparable degree of glutamate-C $4{ }^{13} \mathrm{C}$ enrichment at the study end points (Figure 1E). Differences in the time courses shown in Figure 1E correspond to brain TCA cycle rate differences (see below), which 
A

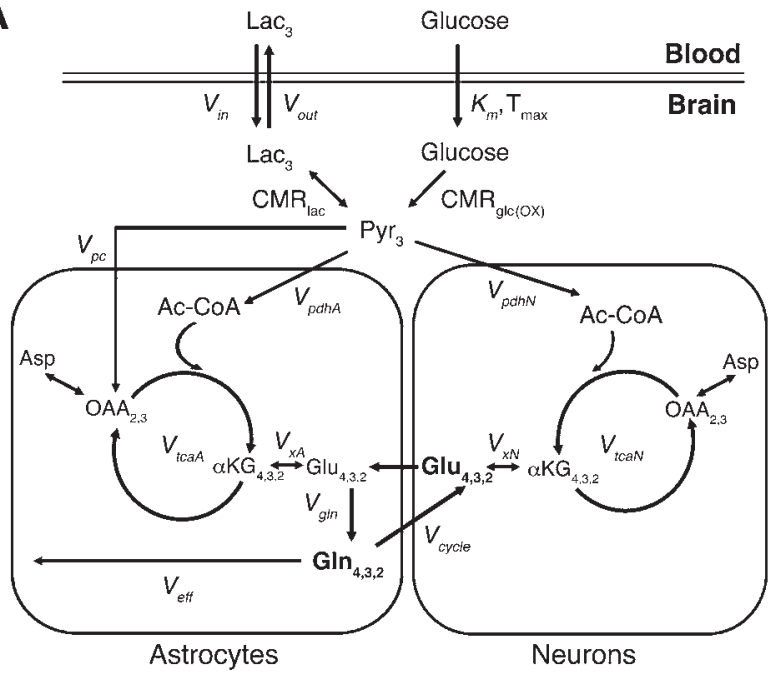

B

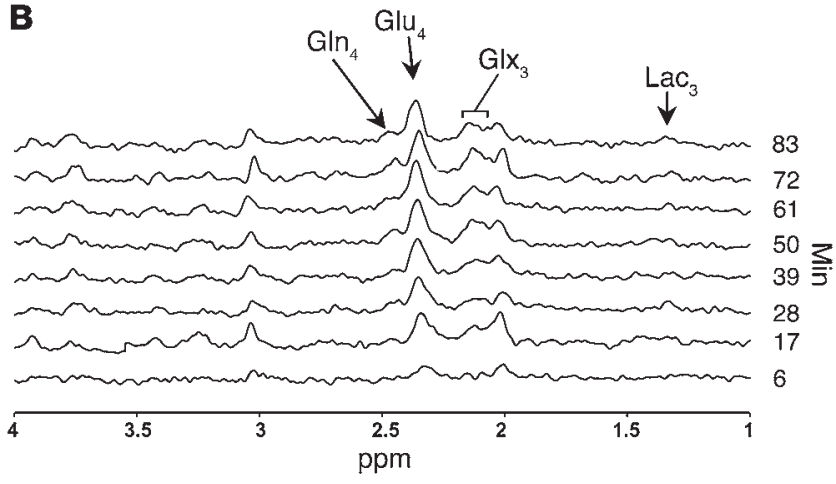

become evident when the absolute metabolite concentrations (Table 1) and corresponding individual plasma lactate levels are taken into account.

In contrast $\left[4-{ }^{13} \mathrm{C}\right]$-glutamine enrichment in both groups reached steady state much slower (Figure 1F), indicating that lactate is first metabolized predominantly in the neuronal compartment in which glutamate is labeled, from which label is then transferred to astrocytes via the glutamate/glutamine neurotransmitter cycle, in agreement with previous results in humans (12) and animal models (20).

Clamped englycemia. Plasma glucose concentrations were maintained at virtually identical levels $(6.3 \pm 0.8 \mathrm{mM})$ in the control and $3 \mathrm{dRH}$ groups during the hyperinsulinemic-euglycemic clamp (Figure 2A). Nevertheless, the rats exposed to antecedent recurrent hypoglycemia required a nearly 2 -fold higher glucose infusion rate to achieve the same level of glycemia (Figure 2B), consistent with their previously reported impaired counterregulatory response (15-17). Plasma glucose ${ }^{13} \mathrm{C}$ enrichment was completely suppressed under these experimental conditions, allowing us to specifically assess the contribution of lactate to brain metabolism alone. While we observed higher plasma lactate levels in the $3 \mathrm{dRH}$ group after initiation of the lactate infusion during the hyperinsulinemic euglycemic clamp, there were no further significant differences in concentration or isotopic enrichment between the 2 groups over the course of the ${ }^{13} \mathrm{C}$-lactate infusion (Figure 2, C and D). After approximately 20 minutes of lactate infusion, $\left[4-{ }^{-13} \mathrm{C}\right]$-glutamate

\section{Figure 3}

Metabolic model and in vivo glutamate enrichment time course together reveal that lactate is predominantly metabolized in neurons. (A) Schematic representation of uptake and relevant metabolic fluxes for $\left[3^{-13} \mathrm{C}\right]$-lactate and glucose in astrocytes and neurons. (B) In vivo POCE difference spectrum showing the increase of ${ }^{13} \mathrm{C}$ labeling in glutamate (Glu) and glutamine (GIn) $\mathrm{C} 3$ and $\mathrm{C} 4$ during infusion of $\left[3^{-13} \mathrm{C}\right]-$ lactate. $\mathrm{Glu}_{4}$, glutamate labeled at $\mathrm{C} 4 ; \mathrm{Gln}_{4}$, glutamine labeled at $\mathrm{C} 4$; $\mathrm{GIx}_{3}$, sum of glutamate and glutamine labeled at $\mathrm{C} 3$; $\mathrm{LaC}_{3}$, lactate labeled at $\mathrm{C} 3 ; \mathrm{T}_{\max }$, Michaelis-Menten constant for glucose transport kinetics; $V_{p c}$, pyruvate carboxylase flux; $V_{x A}$ and $V_{x N}$, exchange rate from $\alpha$-ketoglutarate $(\alpha-K G)$ to glutamate in astrocytes and neurons; $V_{p d h A}$ and $V_{p d h N}$, pyruvate dehydrogenase flux in astrocytes and neurons; $V_{g l n}$, glutamine synthesis rate; $V_{\text {eff }}$, glutamine efflux, set to balance $V_{p c} ;$ Ac-CoA, acetyl-coenzyme A complex.

labeling reached steady state, with animals exposed to recurrent hypoglycemia at slightly lower levels $(P=0.04)$. However, the initial rate of in vivo brain glutamate enrichment, which corresponds to combined pyruvate dehydrogenase and TCA cycle activity, was similar between control and $3 \mathrm{dRH}$ animals $(P=0.8)$ (Figure 2E). Consistent with lactate being predominantly metabolized in the neuronal compartment and label transfer via the glutamate/glutamine cycle to astrocytes, $\left[4-{ }^{13} \mathrm{C}\right]$-glutamine enrichment was slower than that of glutamate and reached steady state after approximately 40 minutes in both groups (Figure 2F).

Antecedent recurrent hypoglycemia increases lactate and glucose oxidation under hypoglycemia. We used a 2-compartment astrocyte/ neuronal metabolic model (Figure 3A), modified to include the kinetics of label transfer from $\left[3-{ }^{13} \mathrm{C}\right]$-lactate to glutamate-C4 and glutamine-C4 labeling (Figure 3B), to calculate neuronal TCA cycle flux $\left(V_{\text {tcaN }}\right)$ and the total contributions of cerebral metabolic rates of glucose oxidation and lactate oxidation $\left(\mathrm{CMR}_{\mathrm{glc}(\mathrm{ox})}\right.$ and $\mathrm{CMR}_{\mathrm{lac}}$, respectively) $(19,21)$. We found a rate of neuronal TCA cycle activity in isoflurane-anesthetized rats of $0.88 \pm 0.07 \mu \mathrm{mol} / \mathrm{g} / \mathrm{min}$ from the euglycemic control group, which was within the range of previous measurements of halothane-anesthetized rats during ${ }^{13} \mathrm{C}$-glucose experiments of 0.52 to $1.2 \mu \mathrm{mol} / \mathrm{g} / \mathrm{min}(19,22)$.

In order to determine the role of physiologically relevant blood lactate levels in support of brain function, we established that the end point brain lactate concentrations from tissue extracts used to calculate metabolic fluxes mirrored those occurring during the acquisition of in vivo experiments (see Supplemental Figure 2). Although under hypoglycemia, control animals had an increased plasma-tobrain lactate gradient, and this was accompanied by a nearly $50 \%$ drop in TCA cycle activity. As a consequence, brain lactate influx $\left(V_{i n}\right)$ in control animals showed no significant difference between EU-clamp and HYPO-clamp conditions $(0.13 \pm 0.05 \mu \mathrm{mol} / \mathrm{g} / \mathrm{min}$ vs. $0.14 \pm 0.05 \mu \mathrm{mol} / \mathrm{g} / \mathrm{min} ; P=\mathrm{NS}$ ). In contrast, unidirectional lactate influx in recurrently hypoglycemic animals was increased by $160 \%$ during hypoglycemia $\left(3 \mathrm{dRH}_{\mathrm{EU}}, 0.10 \pm 0.04 \mu \mathrm{mol} / \mathrm{g} / \mathrm{min}\right.$ vs. $3 \mathrm{dRH}_{\mathrm{HYPO}}, 0.26 \pm 0.04 \mu \mathrm{mol} / \mathrm{g} / \mathrm{min} ; P \leq 0.001$ ) (Figure $4 \mathrm{~A}$ ), suggesting that lactate blood-brain barrier transport was enhanced. There was no statistically significant difference between the $3 \mathrm{dRH}_{\mathrm{EU}}$ group and either control group. To confirm that differences in ${ }^{13} \mathrm{C}$ label influx were due to transporter changes along the blood-brain barrier and not due to differences in the plasmato-brain lactate concentration gradient alone, we normalized the individual $V_{\text {in }}$ values to their corresponding plasma levels (Figure 4B). Similar results were obtained, suggesting that antecedent 
A

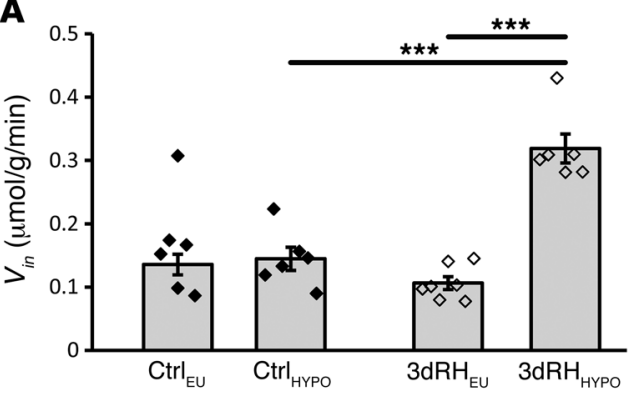

C

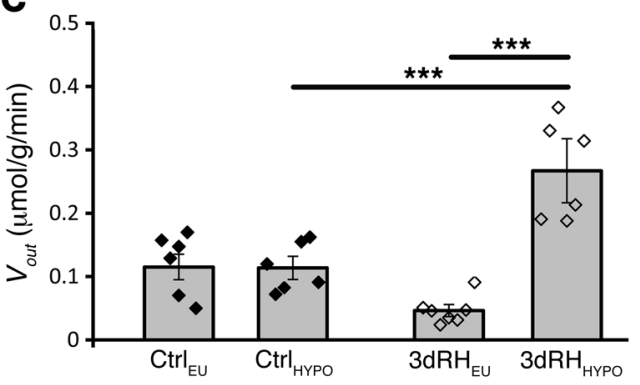

E

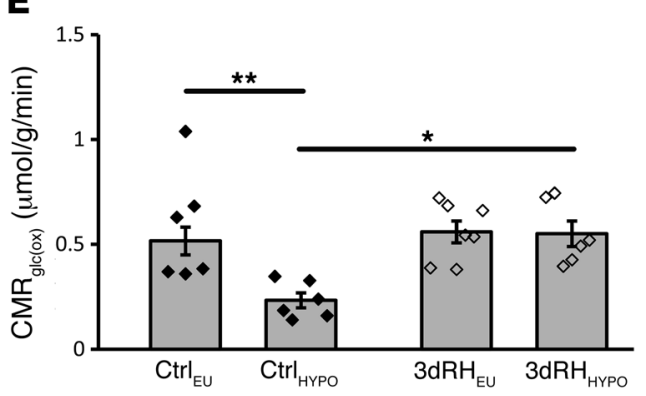

B

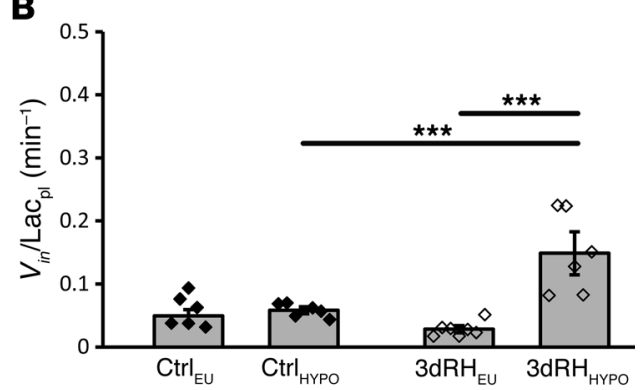

D
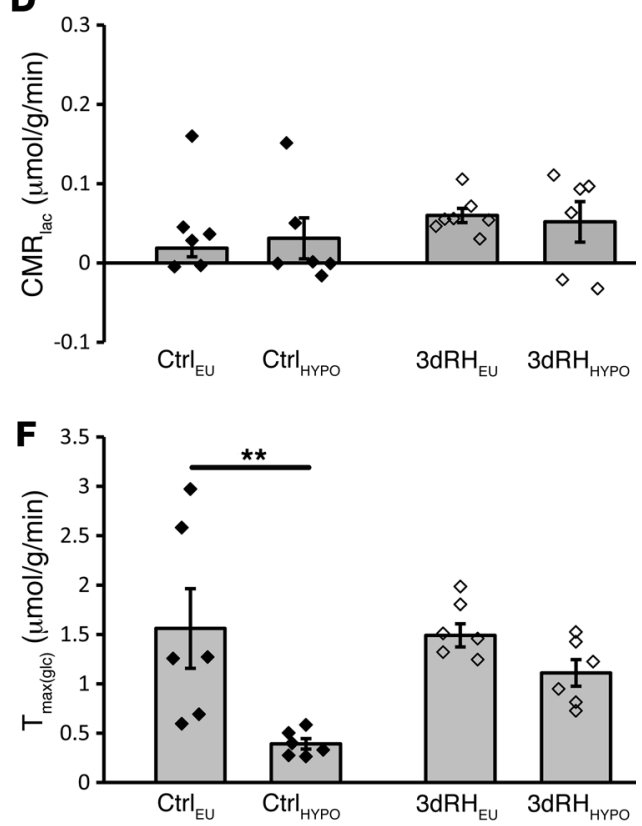

Figure 4

Metabolic fluxes during $\left[3-{ }^{13} \mathrm{C}\right]-$ lactate infusions in control and recurrently hypoglycemic animals under clamped euglycemia and hypoglycemia. (A) Unidirectional lactate uptake from blood to brain $\left(V_{i n}\right)$. (B) Concentration-independent $V_{\text {in }}$ of lactate from blood to brain, reflecting transport changes across the blood-brain barrier $\left(V_{\text {in }}\right)$ $\left.[\mathrm{lac}]_{\mathrm{pl}}\right)$. (C) Unidirectional lactate outflow from brain to blood ( $\left.V_{\text {out }}\right)$. (D) Cerebral metabolic rate of lactate oxidation $\left(\mathrm{CMR}_{\mathrm{lac}}\right)$. (E) Cerebral metabolic rate of glucose oxidation $\left[\mathrm{CMR}_{\text {glc(ox) }}\right]$. (F) Maximal glucose transport capacity into the brain $\left[T_{\max (g \mid c)}\right]$. (G) Neuronal TCA cycle flux $\left(V_{t c a N}\right)$. The data reflect mean \pm SEM. One-way ANOVA was used to calculate statistical significance between all 4 groups. A post-hoc analysis for prespecified comparisons $\left(\mathrm{Ctrl}_{\mathrm{EU}}\right.$ vs. trl $_{\mathrm{HYPO}} ; 3 \mathrm{dRH} \mathrm{H}_{\mathrm{EU}}$ vs. $3 \mathrm{dRH} \mathrm{H}_{\mathrm{HPO}}$; $\mathrm{Ctrl}_{\mathrm{HYPO}}$ vs. $3 \mathrm{dRH}_{\mathrm{HYPO}}$ ) was then used to determine statistically significant difference after Bonferroni correction. Symbols indicate individual rats. ${ }^{*} P \leq 0.05 ;{ }^{* *} P \leq 0.01$; ${ }^{* * *} P \leq 0.001$.

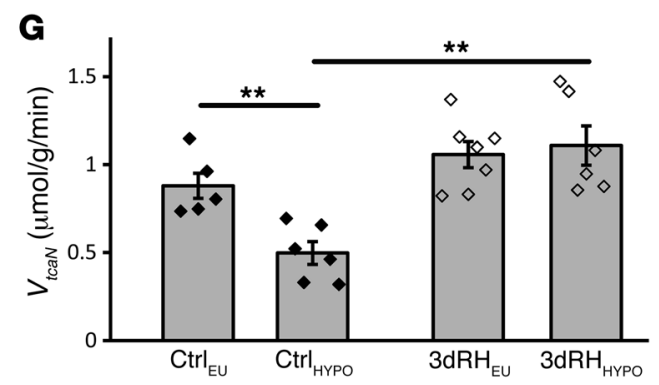

recurrent hypoglycemia increased the functional transport capacity of lactate at the blood-brain barrier.

Following a transient increase in lactate to 3 to $4 \mathrm{mM}$ due to the lactate infusion bolus at the beginning of the study, the steady-state plasma lactate levels achieved $(\sim 2 \mathrm{mM})$ were very similar to the brain intracellular lactate concentrations $(1-1.5 \mu \mathrm{mol} / \mathrm{g})$. This resulted in only a small lactate gradient into the brain. Together with a significant lactate efflux (see $V_{\text {out }}$ in Figure $4 \mathrm{C}$ ), this led to a low net lactate consumption $\left(\mathrm{CMR}_{\mathrm{lac}}\right)$ (Figure $\left.4 \mathrm{D}\right)$ relative to the transport capacity, particularly in the RH animals under hypoglycemia. This may be due to the rats being anesthetized, which decreases brain energy demand relative to awake levels $(23,24)$. Since glucose supply in the $3 \mathrm{dRH}$ animals was not limiting under hypoglycemia, another possible reason for the low contribution of exogenous labeled lactate may be an increase of endogenous glucose-derived (and hence nonlabeled) pyruvate/lactate production. The calculated brain glucose oxidation rate $\left[\mathrm{CMR}_{\mathrm{glc}(\mathrm{ox})}\right]$ during the lactate infusion, on the other hand, differed markedly between the 2 animal groups. In control animals exposed to acute hypoglycemia, we observed a significant decrease in $\mathrm{CMR}_{\mathrm{glc}(\mathrm{ox})}$ compared with euglycemic conditions $\left(\mathrm{Ctrl} \mathrm{EU}_{\mathrm{EU}}\right.$ vs. $\mathrm{Ctrl}_{\mathrm{HYPO}}-54 \% ; P \leq 0.01$ ) (Figure $4 \mathrm{E}$ ). Importantly, this decrease did not occur in the rats with prior exposure to recurrent hypoglycemia $\left(3 \mathrm{dRH}_{\mathrm{EU}}\right.$ vs. $\left.3 \mathrm{dRH}_{\mathrm{HYPO}}\right)$, consistent with a preservation of glucose transport and oxidation after recurrent hypoglycemia. Indeed, when we measured glucose levels in brain extracts at the end of the infusion experiment from the hypoglycemic clamp groups, we found lower glucose in controls $(0.05 \pm 0.01 \mu \mathrm{mol} / \mathrm{g})$ than in $3 \mathrm{dRH}$ animals $(0.25 \pm 0.07 \mu \mathrm{mol} / \mathrm{g})(P<0.05)$, despite comparable 

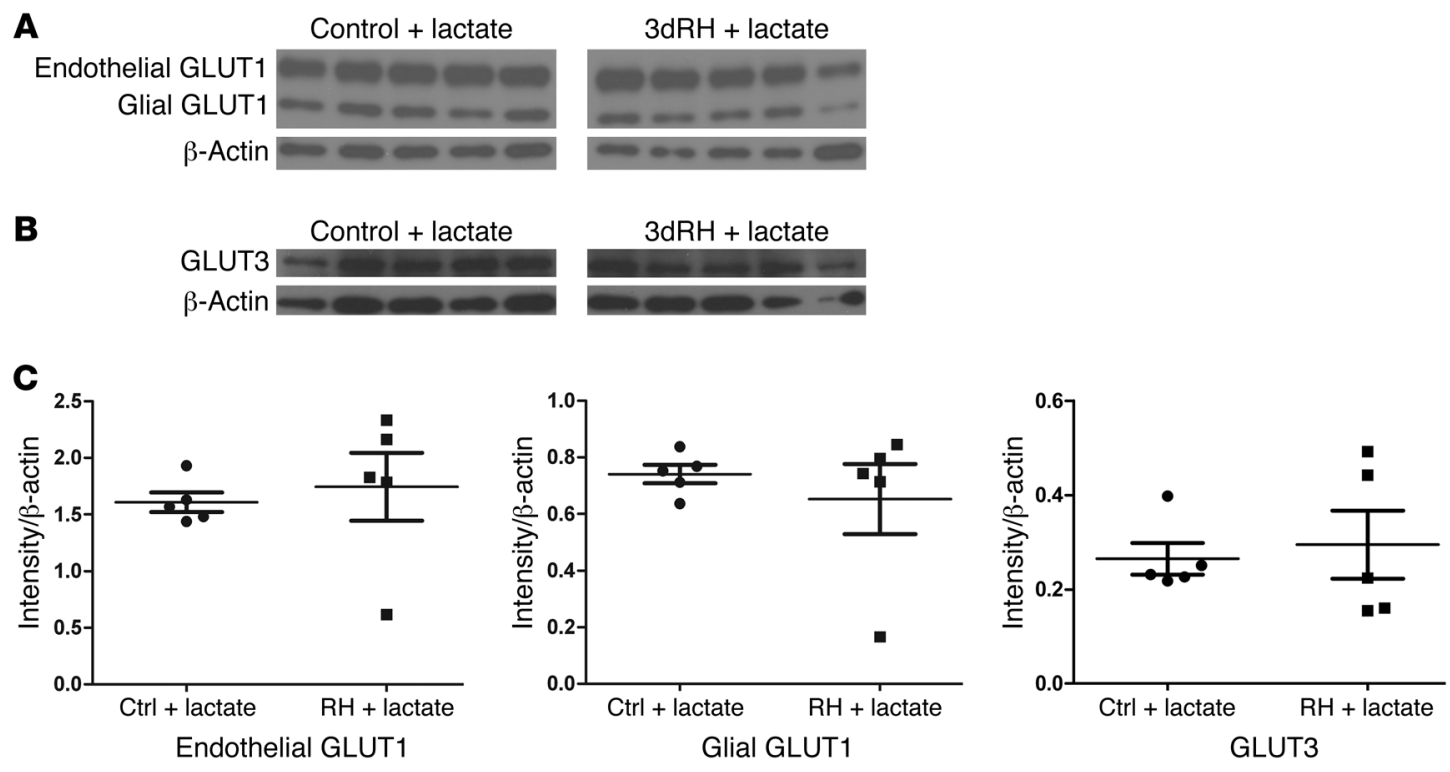

\section{Figure 5}

Glucose transporter expression levels in protein extracts from the brains of hypoglycemic $\mathrm{Ctr}_{\mathrm{HYPO}}$ and $3 \mathrm{dR} \mathrm{H}_{\mathrm{HYPO}}$ animals that received [3-13 $\mathrm{C}$ ]lactate infusions in the NMR experiments remain stable after exposure to recurrent hypoglycemia. (A) Western blot of endothelial and glial GLUT1 isoforms together with $\beta$-actin loading control bands of control and 3dRH animals. (B) Western blot of GLUT3 together with $\beta$-actin loading control bands of control and 3dRH animals. (C) Gel band density ratios of GLUT1 and GLUT3 over $\beta$-actin loading controls. No statistically significant differences were detected between the ratios of control and $3 \mathrm{dRH}$ animals (Student's $t$ test). Data represent mean $\pm \mathrm{SEM}$. Symbols indicate individual rats.

plasma glucose levels $\left(2.6 \pm 0.2 \mathrm{mM}\right.$ Ctrl vs. $2.2 \pm 0.1 \mathrm{mM}^{3} \mathrm{dRH}_{\mathrm{HYPO}}$; $P=\mathrm{NS})$. Using these values and applying them to a recently described 4-state model of glucose transport at the blood-brain

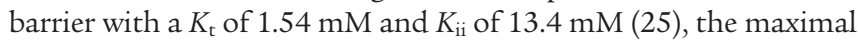
transport capacity $\left(T_{\max }\right)$ in controls at euglycemia $(1.56 \pm 0.40$ $\mu \mathrm{mol} / \mathrm{g} / \mathrm{min}$ ) was significantly higher than that under hypoglyce$\mathrm{mia}(0.39 \pm 0.05 \mu \mathrm{mol} / \mathrm{g} / \mathrm{min} ; P \leq 0.01)$. In contrast, no such difference was observed between euglycemia and hypoglycemic animals in the $3 \mathrm{dRH}$ group $(1.49 \pm 0.12 \mu \mathrm{mol} / \mathrm{g} / \mathrm{min}$ vs. $1.11 \pm 0.14 \mu \mathrm{mol} / \mathrm{g} /$ min; $P=\mathrm{NS}$ ) (see Figure 4F). The resulting ratios of maximum glucose transport/cerebral metabolic rates of glucose $\left[\mathrm{T}_{\max } / \mathrm{CMR}_{\mathrm{glc}(\mathrm{ox})}\right.$ were $2.55 \pm 0.68$ under euglycemia and $1.71 \pm 0.06$ under hypoglycemia in controls and $2.57 \pm 0.36$ under euglycemia and $2.03 \pm 0.09$ under hypoglycemia in $3 \mathrm{dRH}$ animals. The values at euglycemia are in good agreement with published ratios for studies reported in the literature (26-28); interestingly, however, we found that in control animals the low $\mathrm{T}_{\max }$ for glucose under hypoglycemia limited TCA cycle activity. This suggests that functional glucose transport across the blood-brain barrier was already limiting in control animals at a plasma level of $2.5 \mathrm{mM}$, which is consistent with the low brain glucose content cited above, but that this was no longer the case after exposure to recurrent hypoglycemia.

To determine whether this change was caused by differences in blood-brain or neuronal glucose transporter expression levels, we performed Western blots on end point protein extracts from the animals that received the lactate under hypoglycemia during the NMR acquisition, probing for GLUT1 and GLUT3. Since we did not observe enhanced expression levels of either transporter (see Figure 5), the functional restoration of glucose uptake after recurrent hypoglycemia was most likely due to an increase in the activity of existing transporters stimulated by hypoglycemia (29). As shown in Figure
4G, the above changes in glucose and lactate uptake and metabolism together are sufficient to maintain normal neuronal TCA cycle activity under acute hypoglycemia in the rats exposed to recurrent hypoglycemia $\left(3 \mathrm{dRH}_{\mathrm{EU}} 1.1 \pm 0.1 \mu \mathrm{mol} / \mathrm{g} / \mathrm{min}\right.$ vs. $3 \mathrm{dRH}_{\mathrm{HYPO}}$ $1.06 \pm 0.07 \mu \mathrm{mol} / \mathrm{g} / \mathrm{min} ; P=0.87)$ but not in control animals, in which it decreased by $43 \%(P=0.02)$. From this analysis we determined that the major contributor to the sustained TCA cycle in the $\mathrm{RH}$ animals was glucose, despite lactate potentially providing over $30 \%$ of oxidative energy if all of the transported lactate was oxidized.

Under bypoglycemia, lactate rescues neuronal function after exposure to recurrent bypoglycemia. We then determined whether there is a functional correlate to the metabolic findings. To that end, we measured cortical activity in response to forepaw stimulation via extracellular microelectrode during euglycemia (plasma glucose $6.5 \mathrm{mmol} / \mathrm{l})$ and hypoglycemia $(2.1 \mathrm{mmol} / \mathrm{l})$ in separate groups of control and $3 \mathrm{dRH}$ animals ( $n=5$ each) pretreated in the same manner as for the in vivo NMR experiments. During euglycemia both groups of animals showed robust activation of the somatosensory cortex in the form of local multiunit activity (MUA) and local field potential (LFP) responses (Figure 6, A, D, and $\mathrm{G}$ ). In contrast, acute hypoglycemia caused a complete loss of functional reactivity in the control group and partial loss in the animals exposed to antecedent recurrent hypoglycemia (Figure $6, \mathrm{~B}, \mathrm{E}$, and $\mathrm{H}$ ). Intriguingly, infusion of lactate under these hypoglycemic conditions rescued the functional responsiveness of the $3 \mathrm{dRH}$ animals back to baseline levels, whereas this recovery in the control group was only incomplete (Figure 6, C, F, and I). This observation is consistent with our metabolic data, indicating that recurrent hypoglycemia leads to adaptations of both glucose and lactate metabolism that preserve normal neuron function under hypoglycemia. 
A

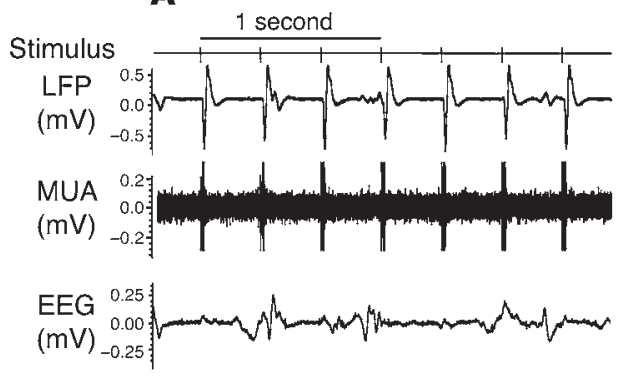

D

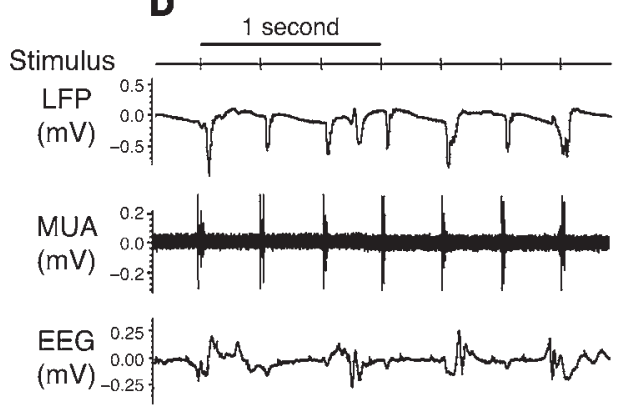

G

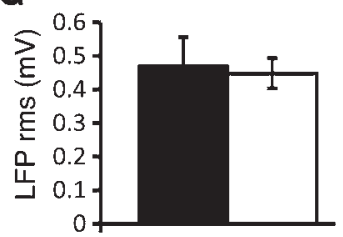

B

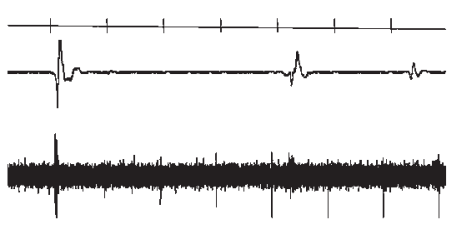

C
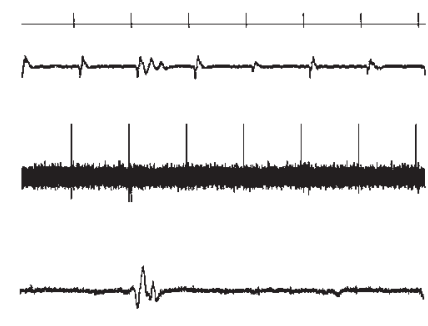

F

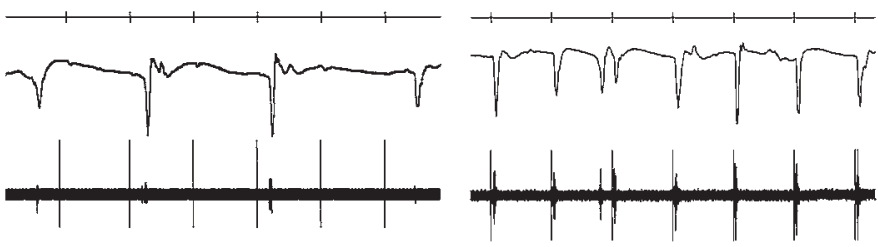

H

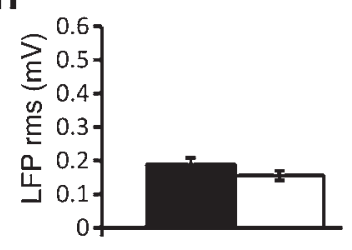

I

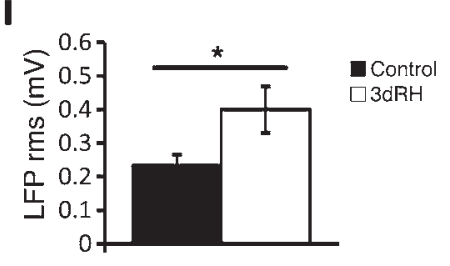

\section{Figure 6}

Lactate normalizes electrophysiological responses under clamped hypoglycemia in 3dRH animals but not in control animals. Representative traces of somatosensory cortical LFPs, MUA, and EEG responses to $3 \mathrm{~Hz}, 2 \mathrm{~mA}$ forepaw stimuli in control and $3 \mathrm{dRH}$ animals under different glycemic conditions: (A) $\mathrm{Ctrl}_{\mathrm{EU}}$; (B) $\mathrm{Ctrl}_{\mathrm{HYPO}}$; (C) $\mathrm{Ctrl}_{\mathrm{HYPO}}$ with lactate infusion; (D) $3 \mathrm{dRH}_{\mathrm{EU}}$; (E) $3 \mathrm{dRH}_{\mathrm{HYPO}}$; (F) $3 \mathrm{dRH}_{\mathrm{HYPO}}$ with lactate infusion. (Note that the initial positive deflection in MUA traces reflect stimulus artifact.) Average of the root mean square LFP responses to forepaw stimuli in control (black bars) and 3dRH animals (white bars) under (G) EU clamp, (H) HYPO clamp, and (I) HYPO clamp plus lactate-infused conditions (6 recordings per animal; $n=5$ per group; comparison by Student's $t$ test; ${ }^{\star} P \leq 0.05$ ).

In order to determine to what degree this effect could be explained by a lactate-mediated increase in cerebral blood flow $(\mathrm{CBF})$ that enhances glucose and alternate fuel delivery, we conducted laser Doppler measurements of CBF under hypoglycemia in control and recurrently hypoglycemic animals. After 60 minutes of a lactate infusion under hypoglycemia, we observed a $20 \%$ increase from baseline in controls and a much more pronounced blood flow enhancement in the $3 \mathrm{dRH}$ animals (Figure 7). We then infused the nitric oxide donor L-arginine (600 mg/kg i.v.) to test whether an increase of $\mathrm{CBF}$ and the concomitant enhanced energy substrate delivery may be sufficient to support neuronal function under hypoglycemia in control animals. We found that after 1 hour of pharmacologically enhanced blood flow (Supplemental Figure 3A) there was no improvement in functional responses (Supplemental Figure $3 \mathrm{~B}$ ), suggesting that, in the control brain during a profound hypoglycemic insult, the CBF enhancement was insufficient to maintain brain glucose above the level at which it became limiting.

\section{Discussion}

In this study, we demonstrate that recurrent exposure to antecedent hypoglycemia increases the unidirectional rate of brain lactate uptake under acute insulin-induced hypoglycemia. Mathematical modeling of metabolic fluxes allowed us to attribute the functional improvement in cortical activity we measured by electrophysiology to a restoration of the neuronal glucose oxidation rate under hypoglycemia to euglycemic levels, which only occurred in the presence of lactate. To our knowledge, this is the first report showing that recurrent hypoglycemia leads to adaptations in energy substrate metabolism that allow lactate to serve as an alternate fuel and to support normal neuronal function during acute hypoglycemia by restoring glucose oxidation.

Previous studies have shown that the brain can use lactate as an energy substrate under various glycemic conditions (11). However, the vast majority were conducted under normal resting conditions at euglycemia. Moreover, often due to technical limitations, the plasma lactate levels were raised during those studies to high normal (4 mM; ref. 30) or supraphysiologic levels (16 mM; ref. 31). While it is known that lactate can reach such high levels during intense anaerobic exercise $(32,33)$, the contribution of more physiologic plasma lactate levels has received much less attention. Our group has recently determined the uptake kinetics for lactate into the human brain under euglycemia (12). In this study, we took 


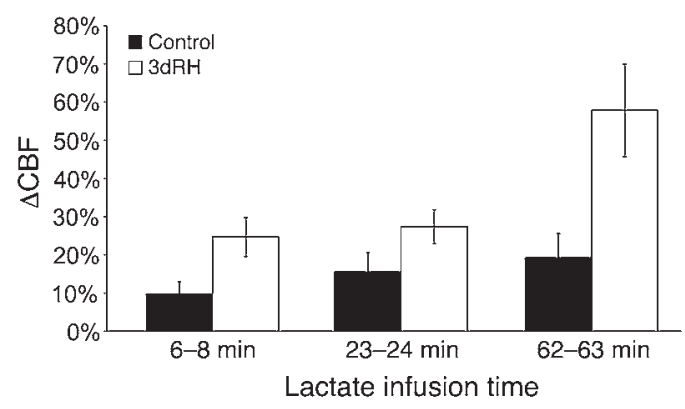

Figure 7

Enhanced lactate-stimulated CBF response under hypoglycemia in control and recurrently hypoglycemic animals. Control (black bars) and $3 \mathrm{dRH}$ (white bars) cortical CBF changes $(\triangle \mathrm{CBF}$ ) in percentage of hypoglycemic baseline, as measured via a laser Doppler flow probe ( $n=5$ per group; $P<0.05$ at each time point).

advantage of an animal model of recurrent hypoglycemia, which recapitulates some of the key aspects of the clinical complications of intensively treated type 1 diabetes, including impaired counterregulatory responses to hypoglycemia $(17,34)$, as well as brain metabolic adaptations $(7,10)$. This model allows better control of glycemic levels during preexposure to hypoglycemia as well as during the experimental procedures.

Basal lactate uptake into the brain in our study at euglycemia $\left(V_{\text {in }}\right.$, $0.14 \mu \mathrm{mol} / \mathrm{min} / \mathrm{g}$ at plasma level $2-3 \mathrm{mM}$ ) is consistent with several other studies that have measured this parameter in the context of rest and exercise in healthy subjects, as summarized by Rasmussen et al. (35). In this study, we found that one of the adaptations to recurrent hypoglycemia was a significant enhancement of lactate uptake $\left(V_{i n}, 0.26 \mu \mathrm{mol} / \mathrm{g} / \mathrm{min}\right)$ into the brain under hypoglycemia (Figure 4A). This finding from the animal model is in agreement with previous observations of enhanced monocarboxylic acid transport across the blood-brain barrier in diabetic patients exposed to frequent hypoglycemic episodes (7). Since we studied nondiabetic animals, our findings show that antecedent recurrent hypoglycemia alone is sufficient to induce increased lactate utilization and that this effect does not require other diabetes-associated effects, such as chronic hyperglycemia. Further studies will be needed to determine the interaction between both of these factors.

In addition to the 2-fold increase in lactate uptake in the $\mathrm{RH}$ animals, we also found that their neuronal TCA cycle flux was 2-fold higher than that in control animals under hypoglycemia. Metabolic modeling revealed that this effect could be attributed to a higher contribution of glucose to neuronal metabolism under hypoglycemia. Indeed, measurement of glucose concentrations and calculation of glucose uptake rates revealed that control animals were limited by transport in their ability to take up sufficient amounts of glucose at a plasma glucose level of $2.5 \mathrm{mM}$ to support normal TCA cycle function, which was not the case after exposure to antecedent recurrent hypoglycemia. This is in contrast to prior reports of healthy and type 1 diabetic humans that underwent a ${ }^{13} \mathrm{C}$-glucose infusion during hypoglycemia, which did not exhibit a significant drop in TCA cycle activity under clamped hypoglycemia (36). However, based on differences in brain glucose concentration among these studies conducted in humans and our study one may have predicted this discrepancy in results: the brain glucose levels during hypoglycemia achieved in human controls and type 1 diabetic sub- jects of 0.5 and $0.6 \mu \mathrm{mol} / \mathrm{g}(37)$ are several times higher than the $K_{\mathrm{m}}$ of hexokinase I (the major brain isozyme) for glucose (0.045-0.07 mM; refs. 38, 39). Thus, brain glucose never became limiting during hypoglycemia and no effect on TCA cycle rate is expected. In contrast, in our study the level of hypoglycemia is more profound, resulting in brain glucose becoming limiting for hexokinase in the controls $(0.05 \mu \mathrm{mol} / \mathrm{g})$, consequently reducing the TCA cycle rate. Our findings, however, are consistent with other previous reports that indicate that under circumstances in which counterregulatory failure can be documented, such as in intensively treated type 1 diabetic patients (40), as well as in our animal model of recurrent hypoglycemia, brain glucose levels are higher due to enhanced glucose transport into the brain (41). However, as discussed below, the higher rate of glucose oxidation depended upon the presence of elevated plasma and brain lactate levels.

Even though our mathematical model of brain metabolism provides a good representation of in vivo and in vitro glucose and monocarboxylic acid transport kinetics (42), it depends on variables that we are currently not able to determine experimentally. This is particularly the case for the subtle nuances of intracellular fuel partitioning and compartmentation. Thus, an uncertainty that potentially limits the degree to which our results can be generalized is that of different intracellular pool sizes of glucose and lactate in astrocytes and neurons, in which the neuronal lactate concentration may be much lower than that measured in whole tissue extracts. However, a large concentration gradient between neuronal, glial, and extracellular fluid lactate pools is highly unlikely given the prior experimental evidence showing that lactate is readily taken up by the neuronal compartment (43) as well as the large transport capacity for lactate in both compartments, which exhibit high MCA transporter activity on their membranes $(20,44)$.

Together, the increase of glucose and lactate uptake following the exposure to recurrent hypoglycemia allowed the brain to maintain the metabolic activity otherwise observed under euglycemic conditions. The electrophysiologic measurements we conducted revealed that these metabolic adaptations are paralleled by a normalization of functional cortical responses to forepaw stimuli under severe hypoglycemia in the $3 \mathrm{dRH}$ animals. As shown in Figure 6B, the control animals lost the majority of their electrical response to stimulation during hypoglycemia in the absence of lactate and had only a partial restoration in the presence of infused lactate (Figure 6C). In contrast, the $3 \mathrm{dRH}$ animals had only a partial loss of their MUA and LFP response (Figure 6E), which was completely restored by the lactate infusion (Figure 6F). The forepaw stimulation paradigm used is known to lead to a substantial increase in metabolic demands in the anesthetized rat somatosensory cortex (in which the electrical measurements were performed). Although we found that lactate was not quantitatively a major net source of fuel for the TCA cycle at rest, the restoration of function in the $3 \mathrm{dRH}$ animals suggests that in the activated state the higher capacity for lactate and glucose transport may become critical in providing the extra oxidative energy needed to sustain the stimulus response. The essential role for lactate in this response is further supported by the fact that an L-arginine-induced increase in CBF and the ensuing enhanced delivery of energy substrates in control animals alone were not sufficient to support neuronal activity under hypoglycemia. Thus, the functional increases of glucose and lactate transport are crucial components of the adaptations to recurrent hypoglycemia that contribute to the preservation of neuronal function. Since we have shown that there was no signifi- 
cant increase in total glucose transporter protein expression following the relatively short-term exposure to $3 \mathrm{dRH}$ (see Figure 5), this points toward other possible mechanisms that may regulate the activity of existing transporters in a more acute manner, as has been suggested by Blodgett and colleagues (29).

In our previous study, providing astrocytes with acetate in control animals allowed glucose to become available for neuronal oxidation under hypoglycemia, as reflected by the higher than normal degree of glutamine enrichment and calculated $\mathrm{CMR}_{\text {glc(ox) }}(10)$, something we did not observe with lactate in this study. In this sense, acetate appears to be able to act as a true alternate fuel that results in glucose sparing under hypoglycemia, making it available for neuronal oxidation. Lactate-infused control animals on the other hand did not benefit from lactate as an alternate fuel under hypoglycemia and showed a decrease in $\mathrm{CMR}_{\mathrm{glc}(\mathrm{ox})}$. This indicates that there was not enough glucose to support neurons, as evident from the very low brain glucose concentration of $0.05 \pm 0.01 \mu \mathrm{mol} / \mathrm{g}$ (see Table 1 ), which is similar to the $K_{\mathrm{m}}$ of hexokinase I for glucose, below which brain glucose becomes limiting for metabolism. Antecedent recurrent hypoglycemia treatment enhanced glucose uptake and, thus, preserved the cortical glucose level at $0.25 \pm 0.07 \mu \mathrm{mol} / \mathrm{g}$ in the presence of lactate, resulting in a neuronal TCA cycle rate that is similar to that in control animals under euglycemia.

In this study, we found that enhanced lactate influx $\left(V_{i n}\right)$ from blood was necessary for preserving glucose metabolism after recurrent hypoglycemia in the hypoglycemic state. As we have shown in the electrophysiologic measurements, this is critical for the maintenance of function, since even if oxidized at the maximum rate of uptake, lactate could only support approximately $30 \%$ of the resting needs of the neuronal TCA cycle $\left(V_{t c a N}\right)$ (Figure 4, A and G).

In conclusion, our findings show that, under insulin-induced hypoglycemic conditions, animals exposed to 3 days of recurrent hypoglycemia have a 2 -fold increase in brain lactate transport. The elevated lactate transport is also associated with the $3 \mathrm{dRH}$ animals being able to sustain the same rate of glucose oxidation and the neuronal TCA cycle, as under euglycemic conditions, a circumstance that we have shown to be caused by a concomitant increase in glucose uptake in this group. Although in the resting state lactate did not substantially contribute to the TCA cycle, under conditions of sensory activation, the increased lactate uptake capacity of the $3 \mathrm{dRH}$ animals may provide the extra oxidative energy needed to restore normal MUA and LFP responses during hypoglycemia. These observations provide the basis for further development of novel neuroprotective therapies to minimize brain injury from severe hypoglycemia in diabetic patients receiving intensive insulin therapy. While lactate itself is unlikely to be used in a clinical setting, we propose that an alternate fuel that has similar uptake and metabolic properties may be helpful in the treatment of hypoglycemia-associated neuronal complications. Taken together, our studies have identified a way to approach the energy substrate deficiency under hypoglycemic conditions and refined the picture of brain alternate fuel metabolism after exposure to antecedent recurrent hypoglycemia.

\section{Methods}

Animal pretreatment. Male Sprague-Dawley rats (220-250 g; Charles River) were housed in the Yale Animal Resource Center, fed a standard pellet diet, and maintained on a 12-hour-day/night cycle. For the recurrent hypoglycemia model, rats were injected with regular insulin (10 units $/ \mathrm{kg}$, i.p.; Humulin R, Lilly) and allowed to undergo controlled hypoglycemia below
$50 \mathrm{mg} / \mathrm{dl}$ (range: $33-50 \mathrm{mg} / \mathrm{dl}$ ) for 3 hours each day for 3 consecutive days, as a rodent model for recurrent hypoglycemia $(3 \mathrm{dRH})$. Nontreated rats served as controls. The following day animals underwent either NMR spectroscopy or electrophysiology measurements ( $n=6$ per group).

$N M R$ spectroscopy. For in vivo NMR experiments, animals were anesthetized with $3 \%$ isoflurane, underwent tracheotomy, and were ventilated with a mixture of $30 \% \mathrm{O}_{2} / 69 \% \mathrm{~N}_{2} \mathrm{O} / 1 \%$ isoflurane via a small animal ventilation system (Harvard Apparatus). The left femoral artery was catheterized for continuous monitoring of blood pressure, plasma sampling, and blood gas analysis. Core body temperature was measured and maintained at $37^{\circ} \mathrm{C} \pm 1^{\circ} \mathrm{C}$ using a water heating pad. Both femoral veins were cannulated for infusion of insulin, glucose, and [ $\left[3-{ }^{13} \mathrm{C}\right]$-lactate via computer-controlled pumps (Harvard Apparatus).

Following positioning in the NMR scanner, animals were brought to a stable euglycemic or hypoglycemic state via a constant $50 \mathrm{mU} / \mathrm{kg} / \mathrm{min}$ insulin and variable $20 \%$ dextrose infusions. Once the target glucose level was reached, a bolus-continuous infusion of $0.35 \mathrm{M}\left[3-{ }^{-13} \mathrm{C}\right]$ lactate was given using a bolus of $1,370 \mu \mathrm{l} / \mathrm{kg}$ body weight, immediately followed by a stepdown infusion of $428 \mu \mathrm{l} / \mathrm{min} / \mathrm{kg}$ that was decreased to $162.8 \mu \mathrm{l} / \mathrm{min} / \mathrm{kg}$ over 20 minutes. Thereafter, a steady-state infusion of $162.8 \mu \mathrm{l} / \mathrm{min} / \mathrm{kg}$ was delivered for the remaining time of the experiment.

In vivo NMR spectra. In vivo NMR spectra were acquired in a 9.4T horizontal bore magnet (Magnex, Scientific) equipped with a 9-cm diameter gradient coil insert ( $490 \mathrm{mT} / \mathrm{m}, 175 \mu \mathrm{S}$; Resonance Research). The magnet was interfaced to a Varian VNMRJ 2.3 console (Varian). Spectra were obtained from a 14-mm diameter surface radiofrequency coil tuned to ${ }^{1} \mathrm{H}(400 \mathrm{MHz})$. ${ }^{13} \mathrm{C}$-inversion and decoupling radiofrequency pulses $(100 \mathrm{MHz})$ were delivered by 2 orthogonally positioned coils driven in quadrature. Localized proton-observed carbon-13-edited (POCE) spectra were obtained from a volume of $180 \mu \mathrm{l}\left(6 \times 6 \times 5 \mathrm{~mm}^{3}\right)$, centered in the middle of the cortex. The POCE difference spectrum contains only resonances from protons linked to ${ }^{13} \mathrm{C}$ atoms, whereas the POCE total spectrum contains all of the proton resonances. Field homogeneity was optimized by adjustment of firstand second-order shims using the automated FASTMAP algorithm (45), achieving a line width at half height of $15 \mathrm{~Hz}$. Localization was achieved with the LASER pulse sequence and water suppression by CHESS 4 (46-48). Spectra were collected with repetition time (TR) of 2.5 seconds (49). At the end of the experiment, animals were removed from the magnet and brains were frozen in situ using liquid nitrogen, while mechanical ventilation was continued to preserve labile metabolites $(50,51)$. Brain extracts and plasma samples for high-resolution NMR spectroscopy were prepared using a procedure described previously $(19,52)$. Metabolite concentrations and ${ }^{13} \mathrm{C}$ enrichments were measured using ${ }^{1} \mathrm{H}-\left[{ }^{13} \mathrm{C}\right] \mathrm{NMR}$ (POCE) at $11.7 \mathrm{~T}$ on a Bruker AVANCE vertical bore spectrometer (Bruker Corp.).

Metabolic modeling. Lactate transport was assumed to follow reversible Michaelis-Menten kinetics. Metabolic fluxes were determined by fitting the 2-compartment model of astrocytic and neuronal metabolism of $\mathrm{C} 4$ and $\mathrm{C} 3$ positions of glutamate and glutamine during infusion of $\left[3-{ }^{13} \mathrm{C}\right]-$ lactate (Figure $3 \mathrm{~A}$ ). Plasma ${ }^{13} \mathrm{C}$-lactate time courses were used as drivers for ${ }^{13} \mathrm{C}$ labeling. Mass and isotopic flows from $\left[3-{ }^{13} \mathrm{C}\right]$-lactate to glial and neuronal glutamate and glutamine pools were expressed as coupled differential equations (Supplemental Table 1) within CWAVE 3.0 software (53) running in MATLAB 7.1. The equations were solved using a first-order Runge-Kutta algorithm, and fitting optimization was achieved using simulated annealing hybridized with a Levenberg-Marquardt algorithm. Bidirectional lactate transport and metabolism were calculated using the following equations: $V_{\text {out }}=V_{\text {in }}-\mathrm{CMR}_{\mathrm{lac}}$ and $\mathrm{CMR}_{\mathrm{lac}}=V_{\text {in }} \times(1-$ [brain lactate $]) / V_{d} /[$ plasma lactate $]$ ), where $V_{\text {out }}$ stands for unidirectional lactate outflow from brain to blood and $V_{d}$ stands for water distribution space.

Electrophysiology and blood flow measurements. Following surgical cannulation performed under isoflurane anesthesia, animals were switched to 
$\alpha$-chloralose for the subsequent measurements. Copper electrodes were inserted subdermally into the forepaws to deliver an electrical stimulus ( $2 \mathrm{~mA}, 3 \mathrm{~Hz}$, for 30 seconds) to activate the somatosensory pathway. After placing the rats on a stereotaxic frame, 2 small burr holes were drilled at the level of the somatosensory forelimb region to measure extracellular neuronal electrical signals as well as blood flow. A high impedance (2-4 M $\Omega$ ) tungsten electrode was inserted into the fourth cortical layer, and a laser Doppler probe with 0.2-mm interoptode distance (Oxford Optronix) was placed adjacent to each electrode. Neural activity was measured in the form of MUA and LFPs. Electrophysiological signals were digitized at $20 \mathrm{kHz}$ and filtered to generate LFP and MUA signals (Krohn-Hite Corp.) by splitting the electrical signals into low- $(<150 \mathrm{~Hz})$ and high-frequency $(0.4-10 \mathrm{kHz})$ bands using a Butterworth filter (24 dB/oct attenuation). LDF signals ( $805 \mathrm{~nm}$; Oxford Optronix) reflecting red blood cell flux, which is related to CBF dynamics, were recorded as described earlier $(54,55)$. Electrophysiological and blood flow data were simultaneously recorded using the CED $\mu 1401$ analog/digital converter and the Spike2 software package (Cambridge Electronic Design).

Western blotting. Protein extracts for Western blot analysis were obtained from the same region of liquid- $\mathrm{N}_{2}$-frozen brain tissue of hypoglycemic control and recurrently hypoglycemic animals, as used for metabolite extractions after lactate infusion. Following protein concentration measurement using a DC Protein Assay Kit (Bio-Rad), equal amounts of total protein were separated by SDS-PAGE. After overnight transfer to nitrocellulose membranes, glucose transporter proteins were detected using anti-GLUT1 $(1: 2,000)$ and anti-GLUT3 (1:2,000) (no. 07-1401, no. AB1344; Millipore Co.), $\beta$-actin $(1: 5,000)$ (no. A5441; Sigma-Aldrich), and goat anti-rabbit HRP-conjugated secondary antibodies $(1: 2,000)$. Following scanning of $\mathrm{x}$-ray films, band intensity ratios to $\beta$-actin were determined using ImageJ (Windows version of NIH Image, http://rsb.info.nih.gov/nih-image/).
Statistics. Data are presented as mean \pm SEM. Where appropriate, a 2-tailed Student's $t$ test or ANOVA with post-hoc testing for prespecified comparisons with Bonferroni correction were used to determine statistical significance $(P \leq 0.05)$.

Study approval. All experimental procedures were performed in accordance with laboratory animal care guidelines and were approved by the Yale Animal Care and Use Committee.

\section{Acknowledgments}

The authors wish to thank Terry Nixon, Scott McIntyre, and Peter Brown for engineering support. We thank Bei Wang and Wanling Zhu for excellent help with the animal preparation. This work was supported in part by grants from the NIH NIDDK (R01DK027121, R01 DA021785, R21 AA018210, R21 AA019803), ARRA supplement (R01 DK027121-28S), NCATS (UL1 RR024139), NINDS (R01 NS037527), NIDDK (R37 DK20495),JDRF (4-2010-433), NINDS (1 P30 NS052519), and NIDDK (P30 DK45735). R.I. Herzog was supported by a YCCI Scholar award (KL2 RR024138) and a career award from NIDDK (K08 DK082618).

Received for publication May 31, 2012, and accepted in revised form January 31, 2013.

Address correspondence to: Lihong Jiang, Yale School of Medicine, MRRC-TAC, N147, PO Box 208043, New Haven, Connecticut 06520-8043, USA. Phone: 203.785.2953; Fax: 203.785.6643; E-mail: lihong.jiang@yale.edu. Or to: Raimund Herzog, Yale School of Medicine, TAC S119, PO Box 208040, New Haven, Connecticut 06520-8040, USA. Phone: 203.737.4773; Fax: 203.737.5558; E-mail: raimund.herzog@yale.edu.
1. [No authors listed]. The effect of intensive treatment of diabetes on the development and progression of long-term complications in insulin-dependent diabetes mellitus. The Diabetes Control and Complications Trial Research Group. NEngl J Med. 1993;329(14):977-986.

2. Cryer PE. Diverse causes of hypoglycemia-associated autonomic failure in diabetes. $N$ Engl J Med. 2004;350(22):2272-2279.

3. Kodl CT, Seaquist ER. Cognitive dysfunction and diabetes mellitus. Endocr Rev. 2008;29(4):494-511.

4. Veneman T, Mitrakou A, Mokan M, Cryer P, Gerich J. Effect of hyperketonemia and hyperlacticacidemia on symptoms, cognitive dysfunction, and counterregulatory hormone responses during hypoglycemia in normal humans. Diabetes. 1994; 43(11):1311-1317.

5. Maran A, et al. Brain function rescue effect of lactate following hypoglycaemia is not an adaptation process in both normal and type I diabetic subjects. Diabetologia. 2000;43(6):733-741.

6. Page KA, et al. Medium-chain fatty acids improve cognitive function in intensively treated type 1 diabetic patients and support in vitro synaptic transmission during acute hypoglycemia. Diabetes. 2009; 58(5):1237-1244

7. Mason GF, Petersen KF, Lebon V, Rothman DL, Shulman GI. Increased brain monocarboxylic Acid transport and utilization in type 1 diabetes. Diabetes. 2006;55(4):929-934.

8. Patel AB, de Graaf RA, Rothman DL, Behar KL, Mason GF. Evaluation of cerebral acetate transport and metabolic rates in the rat brain in vivo using ${ }^{1} \mathrm{H}-\left[{ }^{13} \mathrm{C}\right]-\mathrm{NMR}$. J Cereb Blood Flow Metab. 2010; 30(6):1200-1213.

9. Deelchand DK, Shestov AA, Koski DM, Ugurbil K, Henry PG. Acetate transport and utilization in the rat brain. J Neurochem. 2009;109(suppl 1):46-54.

10. Jiang L, et al. Recurrent antecedent hypoglycemia alters neuronal oxidative metabolism in vivo. Diabetes. 2009;58(6):1266-1274.

11. Tyson RL, Gallagher C, Sutherland GR. ${ }^{13} \mathrm{C}$ Labeled substrates and the cerebral metabolic compartmentalization of acetate and lactate. Brain Res. 2003;992(1):43-52.

12. Boumezbeur F, et al. The contribution of blood lactate to brain energy metabolism in humans measured by dynamic ${ }^{13} \mathrm{C}$ nuclear magnetic resonance spectroscopy. J Neurosci. 2010;30(42):13983-13991.

13. Shulman RG, Hyder F, Rothman DL. Lactate efflux and the neuroenergetic basis of brain function. NMR Biomed. 2001;14(7-8):389-396.

14. Avogaro A, et al. Substrate availability other than glucose in the brain during euglycemia and insulin-induced hypoglycemia in dogs. Metabolism. 1990; 39(1):46-50.

15. Chan $\mathrm{O}$, et al. Increased GABAergic tone in the ventromedial hypothalamus contributes to suppression of counterregulatory responses after antecedent hypoglycemia. Diabetes. 2008;57(5):1363-1370.

16. McCrimmon RJ, et al. Activation of AMP-activated protein kinase within the ventromedial hypothalamus amplifies counterregulatory hormone responses in rats with defective counterregulation. Diabetes. 2006;55(6):1755-1760.

17. Sherwin RS. Bringing light to the dark side of insulin: a journey across the blood-brain barrier. Diabetes. 2008;57(9):2259-2268.

18. Mason GF, Rothman DL. Basic principles of metabolic modeling of NMR $\left({ }^{13}\right) \mathrm{C}$ isotopic turnover to determine rates of brain metabolism in vivo. Metab Eng. 2004;6(1):75-84.

19. Patel AB, de Graaf RA, Mason GF, Rothman DL, Shulman RG, Behar KL. The contribution of GABA to glutamate/glutamine cycling and energy metabolism in the rat cortex in vivo. Proc Natl Acad SciUS A. 2005;102(15):5588-5593.

20. Dienel GA. Brain lactate metabolism: the discover- ies and the controversies. J Cereb Blood Flow Metab. 2012;32(7):1107-1138.

21. de Graaf RA, Rothman DL, Behar KL. State of the art direct ${ }^{13} \mathrm{C}$ and indirect ${ }^{1} \mathrm{H}-\left[{ }^{13} \mathrm{C}\right]$ NMR spectroscopy in vivo. A practical guide. NMR Biomed. 2011; 24(8):958-972.

22. de Graaf RA, Mason GF, Patel AB, Rothman DL, Behar KL. Regional glucose metabolism and glutamatergic neurotransmission in rat brain in vivo. Proc Natl Acad Sci US A. 2004;101(34):12700-12705.

23. Shulman RG, Rothman DL, Behar KL, Hyder F. Energetic basis of brain activity: implications for neuroimaging. Trends Neurosci. 2004;27(8):489-495.

24. Hyder F, Patel AB, Gjedde A, Rothman DL, Behar KL, Shulman RG. Neuronal-glial glucose oxidation and glutamatergic-GABAergic function. J Cereb Blood Flow Metab. 2006;26(7):865-877.

25. Duarte JM, Gruetter R. Characterization of cerebral glucose dynamics in vivo with a four-state conformational model of transport at the blood-brain barrier. J Neurochem. 2012;121(3):396-406.

26. Gruetter R, Ugurbil K, Seaquist ER. Steady-state cerebral glucose concentrations and transport in the human brain. J Neurochem. 1998;70(1):397-408.

27. Seaquist ER, Damberg GS, Tkac I, Gruetter R. The effect of insulin on in vivo cerebral glucose concentrations and rates of glucose transport/metabolism in humans. Diabetes. 2001;50(10):2203-2209.

28. de Graaf RA, et al. Differentiation of glucose transport in human brain gray and white matter. J Cereb Blood Flow Metab. 2001;21(5):483-492.

29. Blodgett DM, De Zutter JK, Levine KB, Karim P, Carruthers A. Structural basis of GLUT1 inhibition by cytoplasmic ATP. J Gen Physiol. 2007;130(2):157-168.

30. van Hall G, et al. Blood lactate is an important energy source for the human brain. J Cereb Blood Flow Metab. 2009;29(6):1121-1129.

31. Nemoto EM, Hoff JT, Severinghaus JW. Lactate uptake and metabolism by brain during hyperlac- 
tatemia and hypoglycemia. Stroke. 1974;5(1):48-53. 32. Dalsgaard MK. Fuelling cerebral activity in exercising man. J Cereb Blood Flow Metab. 2006;26(6):731-750.

33. Gladden LB. Lactate metabolism: a new paradigm for the third millennium. J Physiol. 2004;558(pt 1):5-30.

34. Powell AM, Sherwin RS, Shulman GI. Impaired hormonal responses to hypoglycemia in spontaneously diabetic and recurrently hypoglycemic rats. Reversibility and stimulus specificity of the deficits. J Clin Invest. 1993;92(6):2667-2674.

35. Rasmussen P, Wyss MT, Lundby C. Cerebral glucose and lactate consumption during cerebral activation by physical activity in humans. FASEB J. 2011;25(9):2865-2873.

36. van de Ven KC, et al. Effect of acute hypoglycemia on human cerebral glucose metabolism measured by $\left({ }^{13}\right) \mathrm{C}$ magnetic resonance spectroscopy. Diabetes. 2011;60(5):1467-1473.

37. van de Ven KC, van der Graaf M, Tack CJ, Heerschap A, de Galan BE. Steady-state brain glucose concentrations during hypoglycemia in healthy humans and patients with type 1 diabetes. Diabetes. 2012; 61(8):1974-1977.

38. Sprengers ED, Koenderman AH, Staal GE. Mitochondrial and cytosolic hexokinase from rat brain: one and the same enzyme? Biochim Biophys Acta. 1983; 755(1):112-118.

39. Grossbard L, Schimke RT. Multiple hexokinases of rat tissues. Purification and comparison of soluble forms. J Biol Chem. 1966;241(15):3546-3560.
40. Criego AB, Tkac I, Kumar A, Thomas W, Gruetter $\mathrm{R}$, Seaquist ER. Brain glucose concentrations in patients with type 1 diabetes and hypoglycemia unawareness. J Neurosci Res. 2005;79(1-2):42-47.

41. Herzog RI, Chan O, Yu S, Dziura J, McNay EC, Sherwin RS. Effect of acute and recurrent hypoglycemia on changes in brain glycogen concentration. Endocrinology. 2008;149(4):1499-1504.

42. Simpson IA, Carruthers A, Vannucci SJ. Supply and demand in cerebral energy metabolism: the role of nutrient transporters. J Cereb Blood Flow Metab. 2007;27(11):1766-1791.

43. Itoh Y, et al. Dichloroacetate effects on glucose and lactate oxidation by neurons and astroglia in vitro and on glucose utilization by brain in vivo. Proc Natl Acad Sci U S A. 2003;100(8):4879-4884.

44. Mangia S, Simpson IA, Vannucci SJ, Carruthers A The in vivo neuron-to-astrocyte lactate shuttle in human brain: evidence from modeling of measured lactate levels during visual stimulation. J Neurochem. 2009;109(suppl 1):55-62.

45. Gruetter R, et al. Resolution improvements in in vivo ${ }^{1} \mathrm{H}$ NMR spectra with increased magnetic field strength. J Magn Reson. 1998;135(1):260-264.

46. Garwood M, DelaBarre L. The return of the frequency sweep: designing adiabatic pulses for contemporary NMR. J Magn Reson. 2001;153(2):155-177.

47. Haase A, Frahm J, Hanicke W, Matthaei D. ${ }^{1} \mathrm{H}$ NMR chemical shift selective (CHESS) imaging. Phys Med Biol. 1985;30(4):341-344.
48. Scheenen TW, Klomp DW, Wijnen JP, Heerschap A. Short echo time ${ }^{1} \mathrm{H}-\mathrm{MRSI}$ of the human brain at $3 \mathrm{~T}$ with minimal chemical shift displacement errors using adiabatic refocusing pulses. Magn Reson Med. 2008;59(1):1-6.

49. de GraafRA, Mason GF, Patel AB, Behar KL, Rothman DL. In vivo ${ }^{1} \mathrm{H}-\left[{ }^{13} \mathrm{C}\right]-\mathrm{NMR}$ spectroscopy of cerebral metabolism. NMR Biomed. 2003;16(6-7):339-357.

50. Katsura K, Folbergrova J, Siesjo BK. Changes in labile energy metabolites, redox state and intracellular $\mathrm{pH}$ in postischemic brain of normo- and hyperglycemic rats. Brain Res. 1996;726(1-2):57-63.

51. Ponten U, Ratcheson RA, Salford LG, Siesjo BK. Optimal freezing conditions for cerebral metabolites in rats. J Neurochem. 1973;21(5):1127-1138.

52. Patel AB, Rothman DL, Cline GW, Behar KL. Glutamine is the major precursor for GABA synthesis in rat neocortex in vivo following acute GABA-transaminase inhibition. Brain Res. 2001;919(2):207-220.

53. Mason GF, et al. A comparison of ( $\left.{ }^{13}\right) \mathrm{C}$ NMR measurements of the rates of glutamine synthesis and the tricarboxylic acid cycle during oral and intravenous administration of $\left[1-\left({ }^{13}\right) \mathrm{C}\right]$ glucose. Brain Res Brain Res Protoc. 2003;10(3):181-190.

54. Herman P, Sanganahalli BG, Blumenfeld H, Hyder F. Cerebral oxygen demand for short-lived and steadystate events. J Neurochem. 2009;109(Suppl 1):73-79.

55. Sanganahalli BG, Herman P, Blumenfeld H, Hyder F. Oxidative neuroenergetics in event-related paradigms. J Neurosci. 2009;29(6):1707-1718. 